\title{
THE VIRTUAL BATCAVE: A PROJECT FOR THE SAFEGUARD OF A UNESCO WHL FRAGILE ECOSYSTEM
}

\author{
D. Aiello ${ }^{1}$, A. Basso ${ }^{2}$, M.T. Spena ${ }^{3}$, G. D’Agostino ${ }^{1}$, U. Montedoro $^{4}$, M. Galizia ${ }^{1}$, R. Grasso ${ }^{3}$, C. Santagati ${ }^{1}$
}

${ }^{1}$ Department of Civil Engineering and Architecture, University of Catania, Via Santa Sofia n. 64 95123, Catania, Italy damianoaiello@gmail.com,graziana.dagostino@gmail.com,mgalizia@dau.unict.it, cettina.santagati@dau.unict.it

2 Department of Architecture, Università degli studi G. D’Annunzio Chieti Pescara, Viale Pindaro, 65127, Pescara (Italy) alessandro.basso77@gmail.com

${ }^{3}$ Department of Biological, Geological and Environmental Sciences, University of Catania, rosagra@ hotmail.it, marisaspena@hotmail.com

${ }^{4}$ Microgeo, via Petrarca 42, Campi Bisenzio, Firenze, u.montedoro@microgeo.it

\section{Commission II}

KEY WORDS: Laser scanning, Virtual Reality, Serious Game, Natural Heritage, Photogrammetry, Digital Cultural Heritage

\begin{abstract}
:
This abstract illustrates an interdisciplinary research project which focuses on the study, conservation and enhancement, through 3D digitization and virtual fruition, of an asset of great naturalistic, historical and ethnoanthropological value: Grotta dei Pipistrelli of Pantalica Nature Reserve (Sortino, SR). The cave (located in the Calcinara necropolis) is characterized by a great beauty as well as by a high cultural relevance and a remarkable scientific importance. In 2005, it awarded the UNESCO World Heritage title for its high historic, archaeological and speleological profile. Despite the site is being studied by specialists in chiropterofauna, nowadays there is not a comprehensive and reliable documentation of the plano-altimetric morphology of the cave, able to constitute a 3D database of essential information (e.g. morphological, geological, textural and wildlife information) for current and future studies, and to preserve the memory of this fragile ecosystem. The process of 3D digitization aims to create a model of the cave that allows us to enjoy this place, to explore it and to closely understand it in order to limit the anthropic pressure caused by visitors on the real site. Consequently, it is proposed the creation of a virtual environment, as a reproduction of the real one, which can be enjoyed by all categories of users.
\end{abstract}

\section{INTRODUCTION}

In the last decades, natural heritage - defined as the sum total of the elements of biodiversity, including flora and fauna, ecosystems and geological structures - has been being constantly under threat from a multitude of factors (natural, environmental and anthropic) posing serious risks to its handing down to future generations. The protection and the safeguard of tangible and intangible cultural heritage is a priority not only for the conservation of the identity of a community but also for the generation of wealth and economic growth. In this sense, 3D digital technologies can provide the proper tools to support the documentation and the management of cultural assets through the creation of a $3 \mathrm{D}$ virtual database that recovers all the information on it.

"The Virtual Batcave" project focuses on the study, conservation and enhancement of Grotta dei Pipistrelli (literally, Cave of the Bats), located in Pantalica Nature Reserve (Sortino, SR), through 3D digitization and virtual fruition. It is an asset of great naturalistic, historical and ethnoanthropological value. The Pantalica, Valle dell'Anapo e Torrente Cava Grande Nature Reserve, extended for 3712.07 hectares, was established in July 1997 and covers the area of the Iblei mountains, in south-eastern Sicily. Today, the naturalistic-archaeological site of Pantalica (awarded in 2005, with the city of Syracuse, the UNESCO World Heritage title for its high historic, archaeological and speleological profile) is one of the most important Sicilian protohistoric places, fundamental for understanding the phase of transition from the Bronze Age to the Iron Age on the island.

Grotta dei Pipistrelli is a place characterized by a great beauty as well as by a high cultural relevance and a considerable scientific importance. It hosts the largest bat colony documented in eastern Sicily, including some species at risk (registered in the red list of Italian vertebrates).

Despite being part of a Nature Reserve and protected by a gate in order to preserve the chiropterofauna in it, the cave is often violated due to the entry of unauthorized people. The disturbance caused to the breeding colony (generated, for example, by the introduction of external light sources or by the production of disturbing sounds) could lead to the abandonment of the reproductive site. It is therefore an ecosystem that is as precious as it is fragile.

Starting from these considerations, the need arises to collect in an organic and systematic way the most accurate morphological, geological-material and wildlife information about the cave, with the aim of facilitating future studies and of creating a database able to preserve the memory of this sensitive ecosystem (and make it available even in the event that it no longer exists). The need for a detailed reconstruction of the morphological and spatial components is strongly felt also considering the lack, until now, of a real in-depth survey campaign: in fact, the studies conducted in the recent past have allowed a rough reconstruction of the cave, characterized by a certain level of inaccuracy in the definition of shapes and dimensions. The digital survey made it possible to obtain more accurate results and a better degree of approximation to reality.

The process of digitization has the ambitious goal of creating a model of the cave that allows this site to be explored and understood closely. The second aim of the project is to limit the anthropic pressure caused by visitors to the site. Therefore, it is proposed the creation of a virtual environment, a reproduction of the real one, which can be enjoyed by all categories of users in order to limit the access to the innermost cave's rooms, where the bat colony finds shelter.

This approach, inter alia, can offer a valid example applicable to other artefacts of high historical, artistic or naturalistic value which are difficult to access. In fact, there are many natural and man-made works that fall into this category: for example, the tomb of Nefertari in Egypt, closed to the public in 2003 because the temperature and humidity conditions due to visitors were causing a rapid deterioration of the precious frescoes. 
The complexity of the site required an interdisciplinary approach. The research team consists of experts with different skills and coming from different subject areas (architects, geologists, engineers, zoologists, biologists).

The remainder of the paper is organized as follows: Section 2 will be dedicated to the analysis of the related works, with a specific regard to the surveying of hypogeal environments, their virtual fruition and the enhancement of Cultural Heritage through the serious game's paradigm. Section 3 describes the methodology, the case study and the tested workflow. Then concluding remarks and future activities (Section 4) complete the work.

\section{RELATED WORKS}

In recent years, numerous progress has been made on survey and virtual reproduction of $\mathrm{CH}$. In the research presented here, we have chosen to investigate the potential offered by the methodologies of the integrated digital survey (laser scanning and structure from motion) to know, document and make virtually accessible extreme places such as hypogeal environments. The point clouds obtained are configured not only as real databases, but also as research tools for the detection and monitoring of phenomena that take place inside caves. The main challenge that we try to face in the survey of a site of cultural interest (such as hypogeal environments) is represented , as well as by the proposal of a more accurate and fast acquisition workflow (able to guarantee the minimum impact on the case study), by the obtainment of a reliable replica that can be used as an analysis and monitoring tool and can provide the possibility of enjoying virtually inaccessible places to all categories of users. In this regard, several case studies belonging to three strands of research have been investigated:

- survey of hypogeal environments aimed at the morphologicalspatial documentation;

- projects aimed at enhancing hypogeal environments through surveying and virtual fruition;

- projects related to the virtual fruition of cultural heritage through the serious game's paradigm, in other words gaming experiences aimed at playful learning.

There are numerous studies related to the first strand. Among the most relevant, we mention the research about the Eisriesenwelt (Werfen), the largest ice caves in the world, detected by laser scanner. From the point cloud obtained, a three-dimensional model was created with the aim of monitoring the changes in the hypogeal systems of Werfen (Buchroithner et al., 2011). Furthermore, the complex morphologies of the cave were analyzed, identifying the areas subject to risk thanks to the 3D model (Petters et al., 2011). Finally, the research focused on the possibility of generating a photorealistic 3D model (Milius and Petters, 2012).

In the survey of the Domica Cave in Slovakia (Gallay et al., 2015) and the Catacombs of San Giovanni in Syracuse (Italy) (Bonacini et al., 2013) both research groups have faced the problem of the elaboration and the management of the huge amount of data, of the bad lighting conditions and of the morphological irregularities. In both cases, the researchers have identified a workflow based on the use of digital surveying tools that allows acquiring morphological details that cannot be mapped using traditional methods. Since the point clouds were too dense, it was necessary to significantly decimate them to create the 3D model. In the first case, considering that the model obtained did not exactly respect the morphology of the cave, it was used exclusively for the calculation of the volume of the hypogeal environments; in the second one, a part of the model of the Catacombs was uploaded to the Sketchfab platform for virtual fruition.
Another significant case about the digital survey of hypogeal environments is represented by the Coves de la Saltadora (Coves de Vinromà, Castellón) (Cabrelles López and Lerma García, 2013). The satisfactory results obtained are due to the integration of TLS techniques with the SFM ones.

As mentioned, the data collected from the surveying campaigns, in addition to being a database for future studies, can be used to create virtual simulation experiences. In this way we try to ensure a total fruition of extreme environments to all categories of users. An example of digital surveying of hypogeal environments aimed at virtual fruition is represented by Grotta Gigante of Trieste. The research group proposed a project that allowed knowing the exact morphology of the cave and realizing a virtual tour of the hypogeal environments (Fingolo et al, 2011).

The digitization project of the Paleolithic caves of Biscay (in the Basque countries), on the other hand, used only photogrammetry and a total station to scale and orient the model correctly. The photographic set (obtained by uniformly illuminating the hypogeal rooms with LED lights) and some appropriate adjustments in the tonal curves allowed obtaining the chromatic data and finally using the model in virtual reality (Iturbe et al., 2018).

Serious games for the $\mathrm{CH}$, belonging to the third strand, can help non-specialized users (such as museum visitors, tourists, students, etc.) to live new experiences and expand their knowledge (Anderson et al., 2010; Candy et al. 2014). There are numerous applications developed in recent years in this context. The Priory Undercrofts game aims to look for medieval objects located inside and around the ruins of the Benedictine monastery of Coventry, demolished at the behest of Henry VIII (Doulamis et al., 2011). Another example is the Etruscanning project. The purpose is to recreate and restore the original context of the Regolini-Galassi tomb in the necropolis of Sorbo a Cerveteri, reconstructed in 3D along with the objects found in it and exhibited in the Vatican Museums. A key aspect of this project is the development of natural interaction interfaces: visitors use body movements to explore 3D space and access content without the need for any traditional interface (Pietroni, 2013). MuseUs is an application developed for smartphones that allows users to personalize their museum visit experience (Coenen et al., 2013). The serious game Via Appia is a system of augmented reality within which a kilometer of the ancient Via Appia was reconstructed in three different historical periods. In this way the user can explore the concept of narrative movement by traveling through space and time in the context of a historical site. The app includes quiz games with questions related to information provided by the virtual environment (Liestol, 2014).

The study of these experiences was the starting point for the experimentation presented in these pages. The aim of the project is to create a workflow for a quick and accurate acquisition of hypogeal spaces, to reduce the processing times of the collected data and to generate a virtual environment of high visual quality and with a higher level of immersion and interaction (to be experienced with VR tools).

\section{CASE STUDY: GROTTA DEI PIPISTRELLI IN PANTALICA}

\subsection{Methodology}

The aim of the project is to create a 3D model of the cave that allows this site to be studied and understood closely, as well as to create a virtual immersive environment (following the playful learning's paradigm) to be explored and enjoyed interactively by different categories of users, that can get in contact with this rare ecosystem. 
To achieve these goals, a global knowledge of the cave was required (from a morphological, geological and zoological point of view), and a multidisciplinary and skilled team was set up with a strong collaboration among architects, engineers, speleologists and zoologists.

After the first knowledge step, it was mandatory a suitable survey design, through which the surveying tools were chosen, on the basis of the spatial characteristics, of the current conditions (the impervious position of the cave, the absence of an adequate level of illumination, the impossibility of using artificial light sources in indoor rooms) and of the level of detail to be achieved. Considering the peculiarities of the cave, we chose terrestrial laser scanning integrated with digital photogrammetry. Furthermore, in order to obtain a complete data acquisition, the number of scans to be carried out has been planned. Then, data were collected on site and processed in order to obtain the overall numerical model (the point cloud).

The next step was related to the virtual environment; to create it a workflow was designed and tested. First of all, the point cloud has been transformed into a polygonal mesh. Subsequently, the mesh, simplified and texturized, was used to create the virtual simulation of the cave through the chosen virtual reality software (Unreal Engine).

Therefore, the applied methodology can be summarized as follows:
Knowledge phase
Survey design
Data recording
Data processing
Virtual fruition design
Creation of the virtual immersive and interactive environment

\subsection{Site description}

Grotta dei Pipistrelli, is located in "Pantalica, Valle dell'Anapo e Torrente Cava Grande" Nature Reserve (Sortino, Syracuse, south-eastern Sicily; Fig. 1).

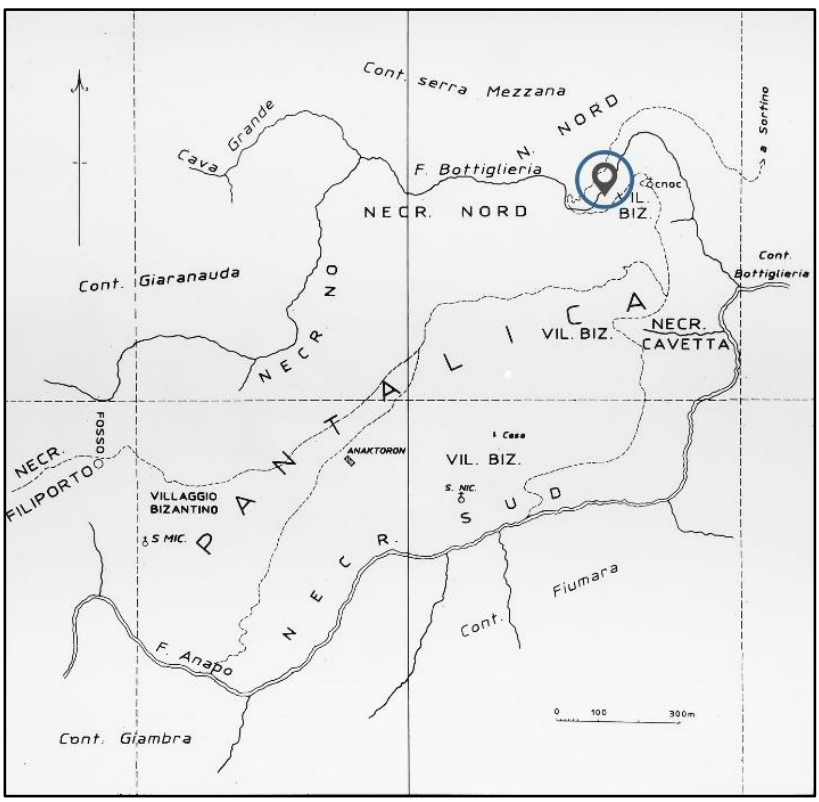

Figure 1. Map of "Pantalica, Valle dell'Anapo e Torrente Cava Grande" Nature Reserve and location of Grotta dei Pipistrelli
The site consists of natural and semi-natural habitats (along with arable land), which are essential for the invertebrate and vertebrate communities.

As stated above, Grotta dei Pipistrelli is so called because it hosts a considerable number of bats (Fig. 2), (Caruso and Grasso, 1996).

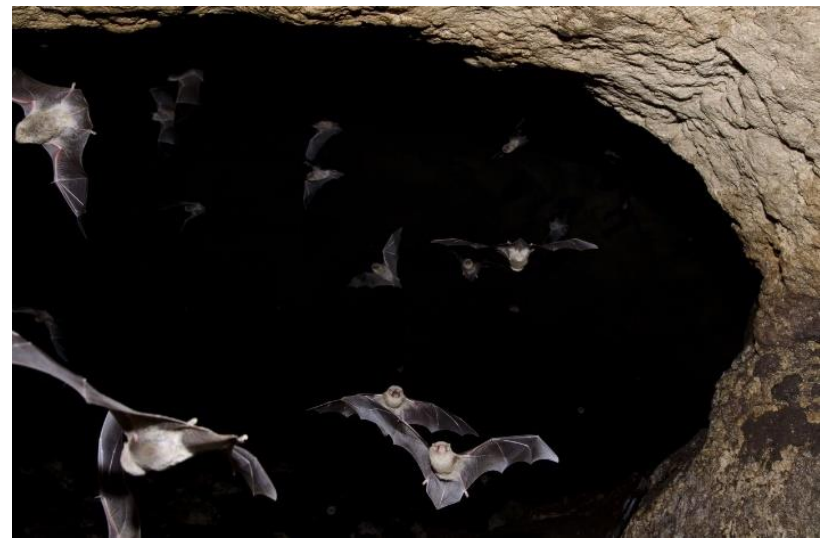

Figure 2. Bats inside Grotta dei Pipistrelli. Picture by T. Puma

The karst cavity opens on a rocky wall overhanging the Calcinara stream, about $10 \mathrm{~m}$ from the watercourse (Fig. 3), in the Miocene "Calcari di Siracusa" formation (Grasso and Lentini, 1982, Schilirò et al., 2002).

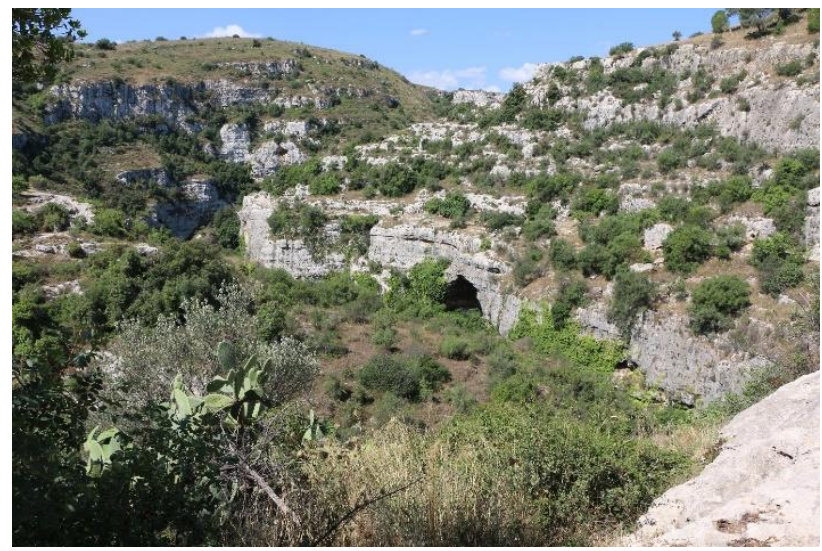

Figure 3. View of Calcinara valley; in the background, the entrance of Grotta dei Pipistrelli

The cavity has a sub-horizontal development with a $7.3 \%$ WE average slope and it has been explored for about $260 \mathrm{~m}$, between the entrance of the cave ( $234 \mathrm{~m}$ a.s.1.) and the ending point (253 $\mathrm{m}$ a.s.l.), where a thick layer of detritus blocks the duct. At the entrance (Fig. 4), the cave has a large opening that quickly shrinks into a funnel leading into a first room.

A gallery links the room to a large hall called "Sala del Guano", with a $30 \mathrm{~m}$ high vault consisting of three domes, which currently host the huge bat colony. The cavity continues with a series of galleries and small dome halls, and it is interrupted in a large terminal hall, where there is a duct enclosed by coarse detritus (Schilirò, 2007). As mentioned, Grotta dei Pipistrelli is mostly known for its large colonies of bats, which by number and importance are among the most numerous in Sicily. It is the only cave systematically monitored to date (Spena et al., 2013). It represents the biggest nursery roost of the region (Spena et al., 2013; Ferrante et al., 2018). Following the methodologies proposed by Agnelli et al. (2006), in January 2012 a monitoring 


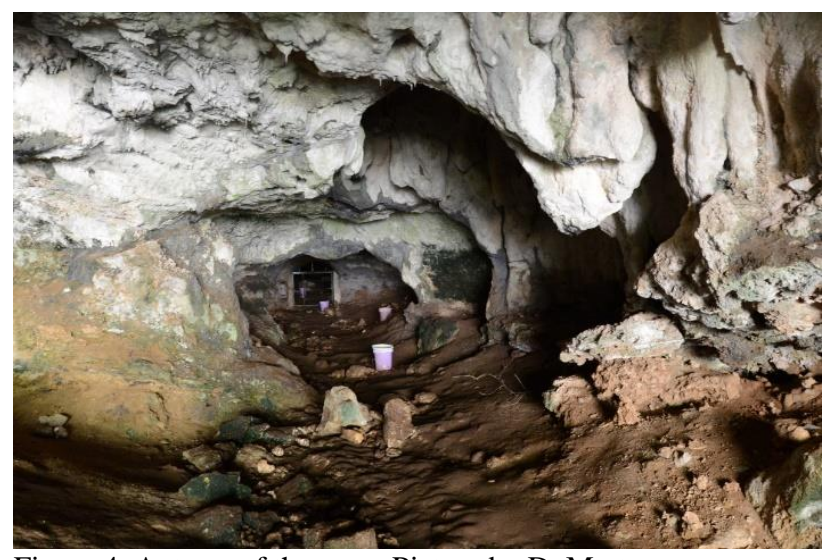

Figure 4. Antrum of the cave. Picture by D. Marturano

programme started to identify the species and to estimate the number of specimens and their seasonality. The following taxa were observed: Rhinolophus ferrumequinum, $R$. euryale, $R$. hipposideros, Myotis myotis, M. blythii, M. capaccinii and Miniopterus schreibersii (Spena et al., 2013). Among them, $M$. schreibersii and the greats Myotis are dominant, while the Rhinolophidae are the rarest. $R$. mehelyi is presumably present in low number of specimens (Caruso and Grasso, 1996, Spena et al., 2013). The maximum number of occurrences (taking into account all the species together) was recorded in summer (over 9,000 in July 2013), while in winter only a few hundred specimens of the genus Rhinolophus were observed. The finding of numerous juveniles in summer makes it possible to hypothesize that those of Grotta dei Pipistrelli are primarily reproductive colonies (Spena et al., 2013, 2017, Grasso et al., in press, Ferrante et al., 2018). In 1996, it was noticed that the walls of the talus (particularly the right wall) had several ossiferous breccia containing many small vertebrates remains (birds, rodents, soricomorphs and mostly bats). The ground close to the right wall also contained osteological evidences of small vertebrate and some bone remains of large mammals (Spena et al., 2017).

\subsection{Digital surveying}

The survey campaign started with a first on-site visit that gave awareness of the difficulty of access to the cave, of the morphology, of the lighting conditions and of the infesting vegetation in the antrum, that was removed before starting the surveying campaign in order to avoid occluded areas. On the basis of the information gathered in this step, the survey project was then prepared. The characteristics of the site, the sequence of the complex and irregular rooms and narrow galleries, the considerable dimensions of the hypogeal environments (in terms of length and height), heavily influenced the choice of the instruments and the techniques to be used.

It has been decided the integrated use of terrestrial laser scanning and digital photogrammetry. Nevertheless, the absence of natural light sources, in combination with the presence of the bat colony, made it difficult to acquire the colour information inside the cave, except for those areas that were sufficiently distant from the colony and could be artificially enlightened.

\subsubsection{Laser scanner survey}

A FARO Focus S70 phase-based laser scanner suitable for being used in wet and dusty environments - IP54 certificated - was used to survey the cave. It has an accuracy range of about $+/-1 \mathrm{~mm}$ at $25 \mathrm{~m}$ and it supports the real time, on-site registration functionality with an acquisition speed of almost 1,000,000 points per second. Another point of strength that led us to choose this scanner was its small size and its easy manoeuvrability, considering the difficulties in accessing the cave (Fig. 5).

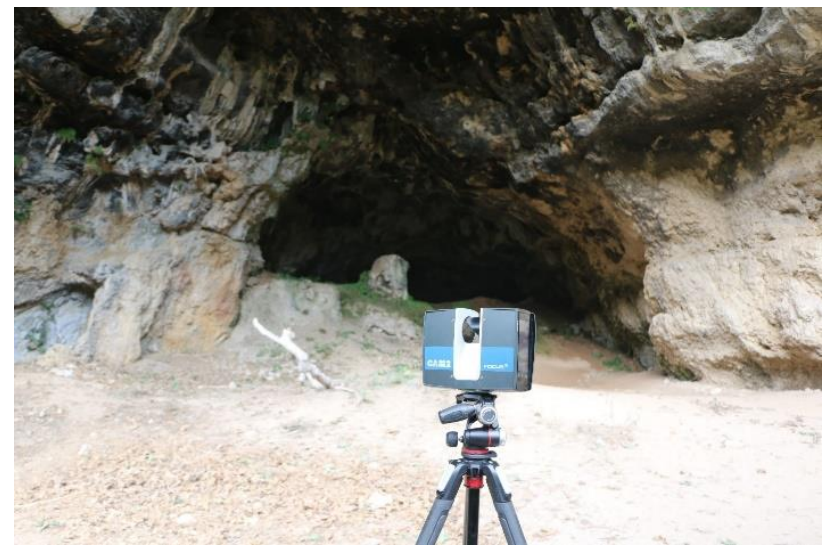

Figure 5. On site acquisition

Once the most suitable tool has been chosen, the recording stations were identified in order to guarantee the maximum coverage during the operational steps. This terrestrial laser scanner allowed recording quickly and accurately most of the complex and dark areas. It was chosen to use it with deactivated camera because of the impossibility to introduce an artificial light source in order not to interfere with the ecosystem.

72 scans with a high degree of overlap (greater than $25 \%$ ) were carried out in order to guarantee a good coverage for the subsequent registration phase (Fig. 6). The survey was particularly complex due to the strong irregularity of the ground, because of which the scanner was difficult to be placed.

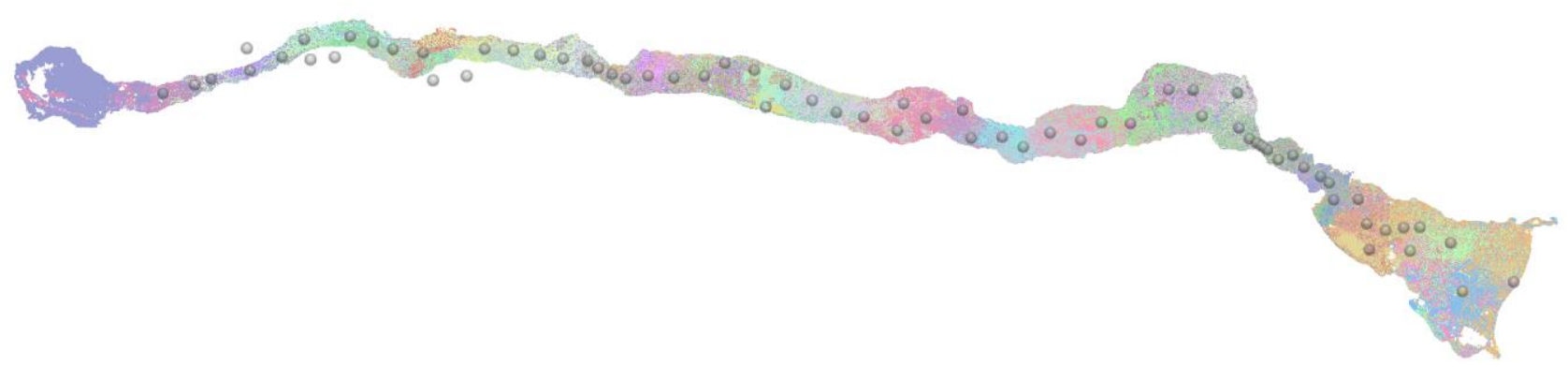

Figure 6. Scans location 


\subsubsection{Photogrammetric survey}

The data acquired through laser scanner, despite having allowed detecting a large part of the cave with an adequate degree of precision, were insufficient in some areas. Moreover, laser scanner has not provided colour information. Consequently, it was decided to integrate point cloud with a photogrammetric survey in order to reconstruct missing information and obtain the chromatic data for the antrum. For this purpose, using a Canon EOS D70 camera, a photographic dataset of the antrum and of the last room of the cave (with a resolution of $5472 \times 3648$ ) was collected. The dataset of the antrum consists of about 1550 photos. This huge number of pictures assured a good coverage and overlapping, solving several on-site shooting issues: excessive slope, presence of noise due to the infesting vegetation (which could not be removed anywhere), high contrast between natural light from outside and the walls of the antrum.

The dataset of the last room, instead, consists of 853 photos. In this case, the photographic survey was possible thanks to the possibility of artificially illuminating the environment through headlights. This is in fact one of the few rooms of the cave where the presence of bats is very small, so it is possible to illuminate the environment without damaging the ecosystem.

\subsection{Data processing}

\subsubsection{TLS data processing}

The scans carried out with TLS were imported into the software SCENE, processed and then automatically recorded using the cloud to cloud method, which identifies the common points to several scans to align them in the correct way (in this case the minimum overlap was $27.3 \%$ ). At the end of this process a point cloud of $1,369,256,920$ points (without any chromatic information) and with an average error of $2 \mathrm{~mm}$ was generated (Fig. 7).

\begin{tabular}{|c|c|}
\hline & Laser scanner survey \\
\hline N. of scans & 72 \\
N. of points & $1,369,256,920$ \\
Minimum average overlapping & $27,3 \%$ \\
Alignment error & $2 \mathrm{~mm}$ \\
\hline
\end{tabular}

Table 1. TLS acquisition information

\subsubsection{Processing of photogrammetric data}

The photographic dataset collected during the survey was then processed using Agisoft Photoscan. The first phase of elaboration consisted in the importation of the sets of photographs and in their alignment, from which a first cloud made by a small number of points (Sparse Cloud) was obtained.

The next phase involved the generation of a dense point cloud, after which the mesh was processed.

Specifically, the point cloud of the antrum consists of 116,547,793 points (Fig. 8). The photographic dataset has been divided into three chunks to facilitate processing.

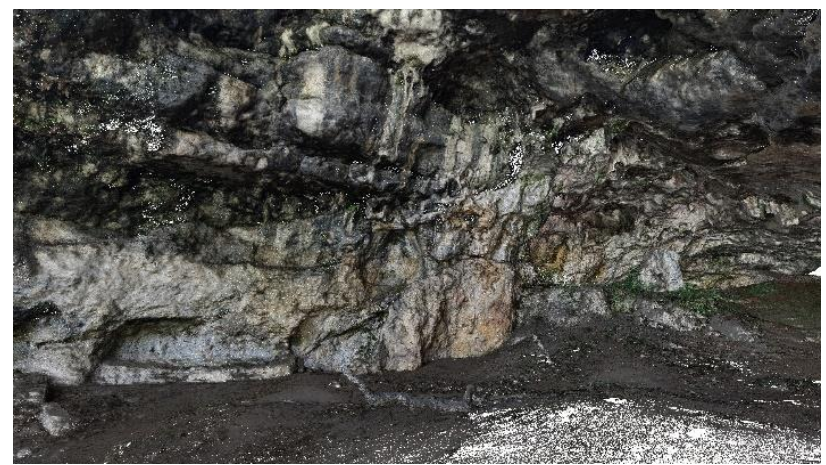

Figure 8 . Dense reconstruction of the antrum

The point cloud of the last room, instead, consists of 148,598,278 points. The complexity of the surfaces, combined with the lack of a suitable light source, has nevertheless prevented reconstructing some parts of the room, which were reinstated with Recap Photo, a software for mesh optimization.

Moreover, from the three-dimensional model obtained, it was possible to reconstruct a photographic quality texture of the cave. In order to standardize the reference systems of the laser scanner point cloud and the photogrammetric mesh, 5 xyz coordinate points, chosen on the basis of significant reference elements and common to both the photogrammetric mesh and the point cloud (for example the graffiti and the material discontinuities), were identified in the three-dimensional photogrammetric model. These points have been associated with the same xyz coordinates of the homologues in the point cloud; in this way, the mesh has acquired the same spatial coordinates of the georeferenced point cloud.
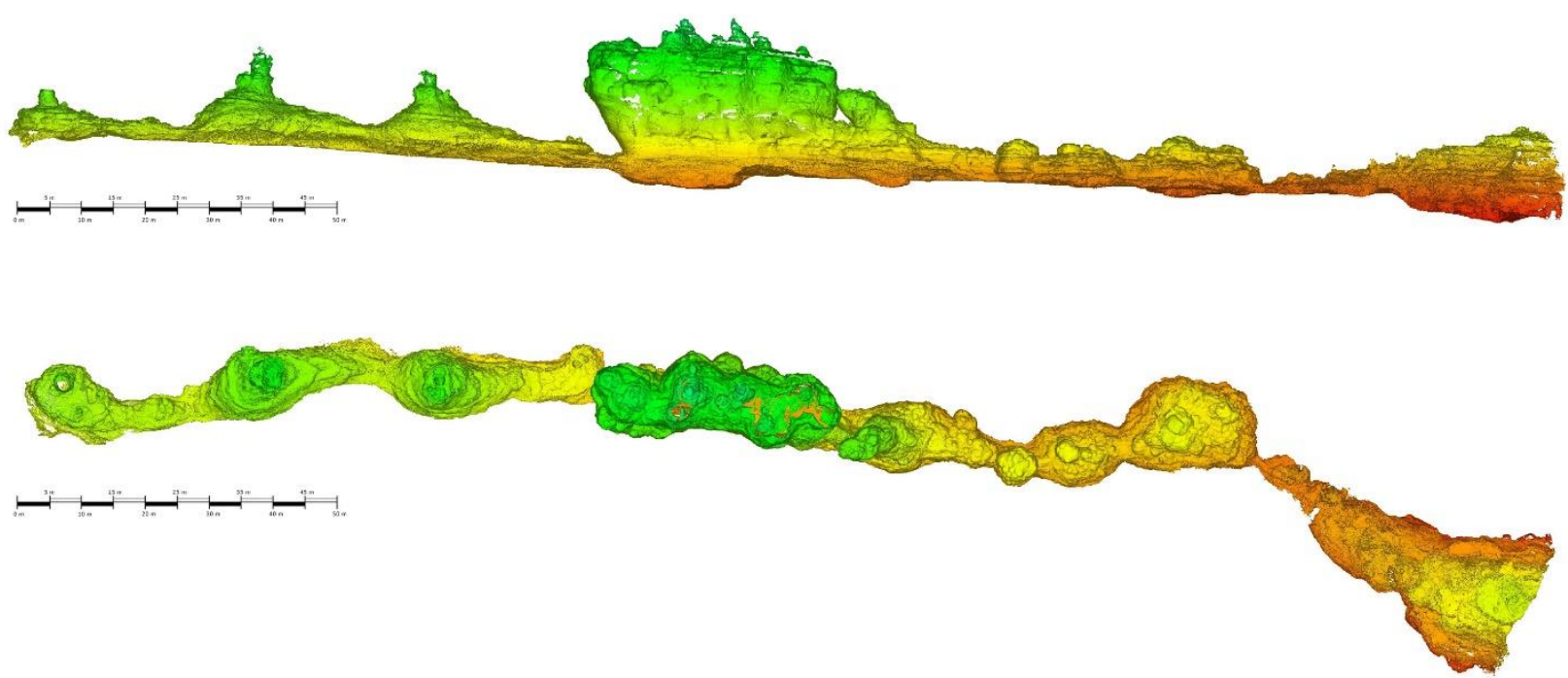

Figure 7. View of the overall model in elevation mode (RGB false colour) 


\begin{tabular}{|c|c|c|}
\hline & Antrum & Last room \\
\hline N. of images & 1550 & 853 \\
Image resolution & $5472 \times 3648$ & $5472 \times 3648$ \\
N. of points & $116,547,793$ & $148,598,278$ \\
N. of mesh polygons & $23,312,008$ & $32,236,842$ \\
\hline
\end{tabular}

Table 2. Photogrammetric models' information

\subsection{Data processing for virtual fruition: workflow for the retopology and texture mapping of the mesh}

The aim of the tested workflow is to create a virtual environment starting from data acquired through digital surveying. The workflow foresees:

detailed mesh creation

mesh optimization (retopology)

UV and texture mapping

Creation of a virtual environment through a game engine

The first step of the workflow has led to test several pipelines for the creation of a detailed mesh model. After having considered both open source software (MeshLab, CloudCompare) and commercial ones (Scene, Recap Pro) on the basis of processing times and the detail level to be achieved, Faro Scene software has been chosen. We decided to work with small portions of the point cloud (21 segmentations), from which we obtained small meshes, more easily manageable than the entire model. Indeed, each portion of the $3 \mathrm{D}$ model preserves the information relative to an absolute reference system, on the basis of which all the coordinates of the model are calculated (in this way, when the portions of the model will be uploaded together in the virtual reality software, they will be placed in the right position, scale and orientation, so as to reconstruct the entire cave). On average, each mesh consists of a polygons number of the order of 6 million. The mesh portions obtained in this way are extremely complex and consist of too many faces to be managed in virtual reality environments (in terms of rendering times and fluidity) and need to be optimized. For this reason, after we detected and solved the mesh issues on Recap Photo (the holes and the particles), these meshes were imported into ZBrush, a digital sculpting tool that combines $3 \mathrm{D} / 2.5 \mathrm{D}$ modelling, texturing and painting, able to manage millions of polygons at once. Through this software it is possible to manage Voxel algorithms and polygonal subdivision. Furthermore, it contains interesting tools of automatic (Z-Remesher) and semi-automatic (topology Brush) retopology. In addition, several plugins allow a balanced optimization of 3D assets and the creation of new UV maps. Therefore, any three-dimensional polygonal model can be easily managed maintaining a high polygonal density.

Once imported, the model has been duplicated in two identical clones: the first one is the target model from which the detail information will be cloned, the second one has been subjected to a retopology operation (Palestini et al., 2017). Through this process it was possible to optimize the number of polygonal faces and change their triangular geometry in a quadrangular mesh, more easily manageable.

In order to clone the level of detail from the first target mesh to the second retopologized one, a polygonal geometric detail projection tool (Project All) has been used. This operation allows exploiting the voxel subdivision tool in order to add polygons to the new geometry maintaining the correct topological morphology. Increasing subdivision levels is not destructive and allows lower polygonal levels to be maintained. To recreate the roughness of the cave surfaces (simulating the complexity without the need to maintain the polygonal model with a high level of detail), a UV map (which allows the texture to be applied to the three-dimensional model) and a normal map were created. The result of this process is a simplified and detailed mesh without chromatic information (Fig. 9).

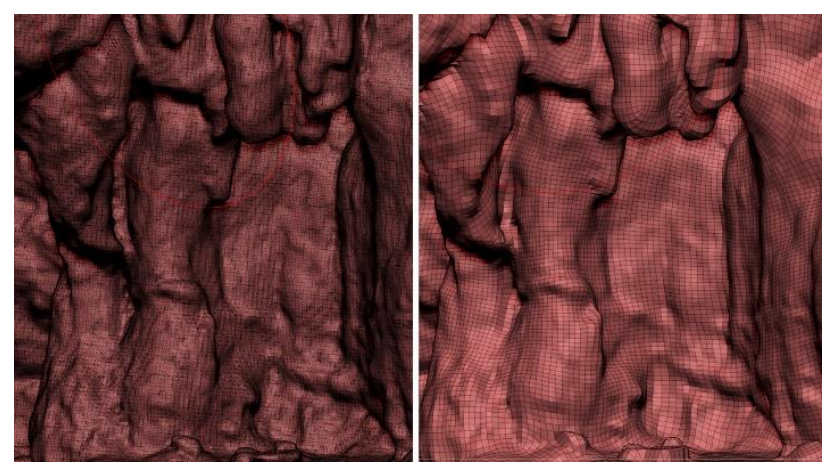

Figure 9. Comparison between the mesh obtained from Scene and the one optimized with ZBrush

In order to reconstruct the colour information, two possibilities have been evaluated:

- the first one allows a more realistic result because it is based on the use of the information contained in the photographic dataset. This method is based on the use of a ZBrush tool called "Spotlight". Once a reference image has been imported, this tool makes it possible to project the chromatic information of the picture directly onto the three-dimensional model;

- the second one ensures a likely result but less realistic than the first one because it is based on the reconstruction of the chromatic data through predefined textures. This method is based on the use of Quixel, a software integrated with Photoshop, which contains a very extensive texture library. These textures can also be combined together to achieve more realistic results by using filters and masks.

After having carried out tests with both methods on small mesh portions, it was decided to adopt the second one, given the greater speed and simplicity of the latter and the acceptable approximation level of the original colour.

Once all the texture channels have been obtained, through a Bridge system (GoZ), the model was imported into Cinema 4D in its lowest polygonal density, consisting of the first subdivision level defined in Zbrush. In Cinema4D it is possible to prepare the model for the Unreal Engine virtual platform. It is important to check the direction of the normals of the mesh polygons because, during the editing and the retopology, it can happen that they are flipped. This leads to a wrong polygons visualization and it causes problems associated with graphic rendering and incorrect lighting during the baking of the light map in Unreal.

The most popular digital formats that allow a better exportimport, aimed at managing assets for interactive platforms, are the .obj and the .FBX Autodesk, which is able to preserve all the material and textural information previously assigned.

\subsection{Virtual reality project}

In the end, the model of the cave was imported into Unreal Engine 4, one of the most used virtual platforms. Its real-time graphics technology in the latest releases reaches levels of photorealism increasingly similar to those of the most famous pre-calculated rendering engines based on CPU processors, such as V-Ray, Arnold Render and Corona. The virtual simulation has been built with a degree of likelihood as high as possible. In this regard, the virtual environment has been recreated in full scale and the mesh has not overly been simplified; the perception of 
the exact proportions increases the sense of presence and allows the three-dimensional model to be used for scientific purposes.

The fluidity of the virtual experience has been highly considered, given that in VR simulation it is appropriate to guarantee a frame rate from 60fps up to avoid disorientation and simulator sickness. The first goal that the virtual simulation tried to achieve was to allow the whole cave to be visited. The second fundamental goal was to associate metadata with the most interesting components of the case study in order to transmit information about its morphology, the ecosystem it hosts (with particular reference to the bat colony and the risk factors to which it is subjected), its geological genesis and the fossil remains found in the walls of the talus. The third goal was to allow the user to interact with the virtual environment through the manipulation of the surrounding objects (like the torch to illuminate the cave's rooms).

The virtual experience starts from the antrum, illuminated by direct sunlight. The antrum, where you can look out onto a natural landscape, tries to recall the real view of the Calcinara valley, with the rocky slope covered by dense vegetation. In the background, it is possible to hear the sounds of the surrounding environment.

The visitor is accompanied by a voice-over narration that gives information about the history and the morphology of the cave. Among the various possibilities explored in the design of virtual fruition project, we decided to allow the user to live an experience similar to the real one. For this reason, proceeding inside of the hypogeal environments, natural light decreases until the cave is left in complete darkness as it is in reality. In order to continue the virtual visit, the user can grab a torch that he will find along his way and which will dimly illuminate the deepest rooms of the cave (Fig. 10).

The voice leads the visitor to the biggest room, the "Sala del guano", where the high ceiling is populated by the bat colony. Here the sense of immersion is increased by the possibility to see some specimens of bats in flight and to hear their screech.

You can proceed further until you reach the last hypogeal room, where the visit ends in front of the occluded conduit, never excavated, beyond which other unexplored rooms could be hidden.

\section{CONCLUSIONS}

The prototype created for the study, the conservation and the virtual fruition of Grotta dei Pipistrelli in Pantalica has allowed testing multiple workflows related to:

3D acquisition of underground spaces in hostile conditions (difficulties in accessing, poor lighting, presence of fauna, extreme thermo-hygrometric conditions, complex rooms articulation);

optimization of the polygonal model aimed at creating a virtual simulation through game engines;

acquisition of photographic texture for an exhaustive documentation of the state of conservation.

The chiropterofauna's presence led to some choices that subsequently influenced the texture elaboration. Indeed, it was not possible to obtain a texture that faithfully reproduced the materiality of the cave's surfaces. In the future, algorithms for the automatic colouring of the model starting from the acquired data (through laser scanner and photogrammetry) and specific photographic techniques will be tested.

The experimentation conducted so far and the first assessment tests (Fig. 11) demonstrate that the virtual prototype (aimed at protecting an ecosystem of high natural, scenic, historical and ethno-anthropological value, as well as at providing a valid tool for studying and analysing the morphology of the cave) can become part of a risk factor mitigation strategy that is not limited to traditional methods, but is based on an alternative fruition principle, reclaimed precisely in the virtual dimension.

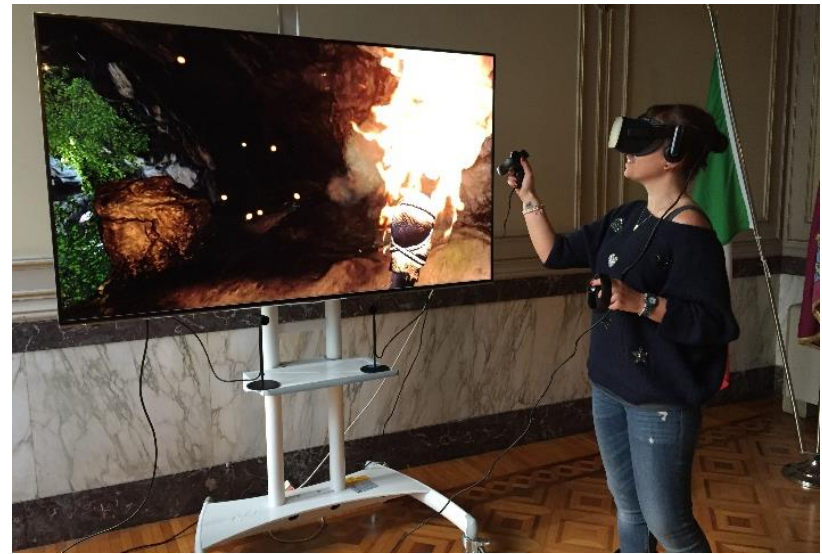

Figure 11. User experience testing

\section{ACKNOWLEDGEMENTS}

The authors would like to acknowledge Dr. Filadelfo Brogna, manager of the "Dipartimento Regionale Azienda Foreste Demaniali di Siracusa - UPA di Siracusa" and in charge of the Nature Reserves: Vendicari, Cavagrande del Cassibile, Pantalica/Valle dell'Anapo for providing the access to Grotta dei Pipistrelli.
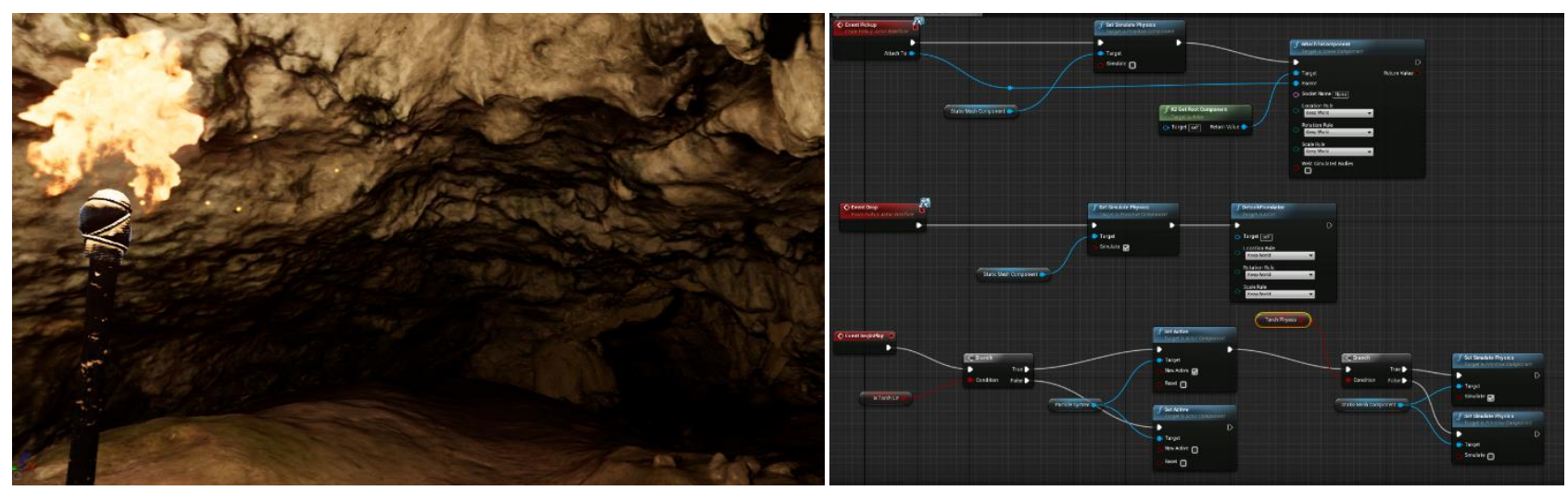

Figure 10. On the left, view of the virtual reconstruction of the cave (taken from Unreal Engine). On the right, the node-based system of Unreal Engine used to obtain the interaction with the torch 


\section{REFERENCES}

Agnelli, P., Patriarca, E. and Martinoli, A., 2006. Bat species occurring in Italy. In: Agnelli, P., Martinoli, A., Patriarca, E., Russo, D., Scaravelli, D., Genovesi, P. (Eds), Guidelines for bat monitoring: methods for the study and conservation of bats in Italy. Quad. Conserv. Natura 19 bis, Min. Ambiente - Ist. Naz. Fauna Selvatica, pp. 12-86.

Anderson, E., McLoughlin, L., Liarokapis, Peters, F., C., Petridis,P., and De Freitas, S., 2010. Developing Serious Games for Cultural Heritage: A State-of-the-Art Review. Virtual Reality 14(4).

Bonacini E., D’Agostino G., Galizia M., Santagati C., Sgarlata M., 2013. Hidden cultural landscapes: survey and digital enhancement of the catacombs of San Giovanni in Syracuse. In: Gambardella C. (ed), Heritage architecture landesign focus on conservation regeneration innovation. Le vie dei Mercanti__ XI Forum Internazionale di Studi, Napoli, pp. 262 - 271, La Scuola di Pitagora

Buchroithner M.F., Milius J. \& Petters C., 2011. 3D surveying and visualization of the biggest ice cave on earth. In: Proceedings of 25th International Cartographic Conference. Paris, France, 38 July 2011.

Cabrelles López, M., \& Lerma García, J. L., 2013. Documentación 3D de abrigos rupestres a partir de láser escáner y de procesos fotogramétricos automatizados. Virtual Archaeology Review, 4(8), 64-68.

Candy L., and Ferguson S. (Eds.), 2014. Interactive Experience in the Digital Age, New York, Springer.

Caruso, D. and Grasso, R., 1996. La fauna delle grotte. In: Ragonese, B. (ed.), Atti del Convegno "La fauna degli Iblei", Noto (SR) 13-14 maggio 1995, Zangara Stampa, Siracusa, pp. 201-281.

Coenen T., Mostmans L., Naessens K, 2013. MuseUs: Case Study of a Pervasive Cultural Heritage Serious Game. ACM Journal on Computing and Cultural Heritage, Vol. 6, No. 2, Article 8.

Doulamis A., Liarokapis F., Petridis P. and Miaoulis G., 2011. Serious Games for Cultural Applications. Intelligence Computer Graphics, pp. 97-115.

Ferrante, M., Spena, M.T., Hernout, B.V., Grasso, A., Messina, A., Grasso, R., Agnelli, P., Brundo, M.V. and Copat, C., 2018. Trace elements bioaccumulation in liver and fur of Myotis myotis from two caves of the eastern side of Sicily (Italy): A comparison between a control and a polluted area. Environ. Pollut., Vol. 240, pp. 273-285.

Gallay, M., Kaňuk J., Hochmuth Z., Meneely J. D., Hofierka J. and Sedlák V., 2015. Large-scale and high-resolution 3-D cave mapping by terrestrial laser scanning: a case study of the Domica Cave, Slovakia. International Journal of Speleology, 44(3), pp. 277-291.

Grasso, M. and Lentini, F., 1982. Sedimentary and tectonic evolution of the eastern Hyblean plateau (southeastern Sicily) during Late Creataceous to Quaternary time. Paleogeography Palaeoclimatology Palaeoecology, 39, pp. 261-280. https://doi. org/10.1016/0031-0182(82)90025-6.
Grasso, R., Agnelli, P., Brogna, F., Frittitta, C. and Spena, M.T., in press. La chirotterofauna della Grotta dei Pipistrelli (SR). In: Atti del $5^{\circ}$ Congresso Regionale di Speleologia, Santa Ninfa (TP), 23-24 novembre 2013

Iturbe A., Cachero R., Cañal D., Martos A., 2018. Digitalización de cuevas con arte paleolítico parietal de bizkaia. Análisis científico y divulgación mediante nuevas técnicas de visualización. Virtual Archaeology Review, 9 (18), pp. 57-65.

Liestøl G., 2014. long the Appian Way. Storytelling and Memory across Time and Space in Mobile Augmented Reality. In: EuroMed 2014, LNCS 8740, pp. 248-257.

Milius J. and Petters C., 2012. Eisriesenwelt - From Laser Scanning to PhotoRealistic 3D Model of the Biggest Ice Cave on Earth. In: Jekel T., Car A., Strobl J. \& Griesebner G. (Eds.), GIForum 2012: Geovisualization, Society and Learning. Wichmann Verlag, Berlin, pp. 513-523.

Paganini P., Fingolo M., Facco L., Ceccato A., Breganze C., Cezza M., 2011. Tra realtà virtuale e rilievi 3D ad alta risoluzione. Veneto Geologi, pp. 21-25.

Palestini C., Basso A., 2017. The photogrammetric survey methodologies applied to low cost $3 \mathrm{~d}$ virtual exploration in multidisciplinary field. In: Int. Arch. Photogramm. Remote Sens. Spatial Inf. Sci., XLII-2/W8, 195-202.

Petters C., Milius J. \& Buchroithner M.F., 2011. Eisriesenwelt: Terrestrial laser scanning and $3 \mathrm{~d}$ visualization of the largest ice cave on Earth. In: Proceedings European LiDAR Mapping Forum, Salzburg, Austria, pp. 1-8.

Pietroni E., 2013. Natural interaction in VR environments for cultural heritage: the virtual reconstruction of the RegoliniGalassi tomb in Cerveteri. Archeologia e Calcolatori, 24. pp. 231-247.

Schilirò, F., Ruggieri, R. and Cannata, A., 2002. Necropoli di Pantalica: Carsismo e processi cinematici sul versante nordorientale del Torrente Calcinara. Speleologia Iblea, 10, pp. 5974

Schilirò, F., 2007. Stato tensionale nelle grotte carsiche di Pantalica (Grotta dei Pipistrelli). Speleologia Iblea, 12, pp. 161170.

Spena, M.T., Allegra Filosico, M., Brogna, F., Dipasquale, C., Puma, A., Grasso, R. and Agnelli, P., 2013. I chirotteri della Grotta dei Pipistrelli (SR): un unicum nella Sicilia sud-orientale. In: Atti della Società dei Naturalisti e Matematici di Modena, Vol. 144, p. 171.

Spena, M.T., Agnelli, P., Di Maita, J., Grasso, R., Reitano, A., Santoro, C. and Salari, L., 2017. Pleistocene bats (Mammalia, Chiroptera) from Grotta dei Pipistrelli (southeastern Sicily, Italy). Preliminary report. Barbastella J. Bat Res., 10 (1), pp. 3741. 